\title{
Acidic Sugar Degradation Pathways - An ab initio Molecular Dynamics Study
}

\author{
Xianghong Qians", Mark R. Nimlos, David K. Johnson, and Michael E. Himmel \\ ${ }^{s} R x$-Innovation, Inc., Fort Collins, CO 80525 \\ National Bioenergy Center, National Renewable Energy Laboratory, Golden, CO 80401
}

\begin{abstract}
Ab initio molecular dynamics (MD) simulations were employed to elucidate xylose and glucose degradation pathways. In the case of xylose, a 2,5-anhydride intermediate was observed leading to the formation of furfural through elimination of water. This pathway agrees with one of the mechanism proposed in the literature in that no open chain intermediates were found. In the case of glucose, a series of intermediates were observed before forming the 2,5anhydride intermediate that eventually leads to hydroxymethylfurfural (HMF). One of these intermediates was a very short-lived open chain form. Furthermore, two novel side-reaction pathways were identified which lead to degradation products other than HMF.
\end{abstract}

Keywords: degradation, pathway, acidic, intermediate, sugar

\section{Introduction}

Loss of fermentable sugars to acidic degradation is one of the primary concerns for the chemical prehydrolysis of lignocellulosic biomass. The decrease in yield of xylose and glucose during prehydrolysis could significantly affect the economic viability of these processes. In order to improve the yields of sugar products, particularly during dilute acid prehydrolysis, understanding the sugar degradation pathways at the molecular level is critical. Today, review of the literature reveals numerous studies of sugar degradation mechanisms in acidic media based on experiments, but few using kinetic modeling [Abatzoglou et al 1986, Antal et al 1990a, Antal et al 1990b, Antal et al 1991, Bouchard et al 1992, Garrett et al 1969, Johnson\&Davis 2003, Lee et al 2001, McKibbins et al 1962, Mok et al 1992, Parker et al 2000, Torget et al 2000, van Dam et al 1986]. It was commonly thought that furfural and hydroxymethylfurfural (HMF) are by far the principal acidic degradation products for xylose and glucose, respectively. However, furfural and HMF production only account for a portion of the sugar loss observed during pretreatment [Abatzoglou et al 1986, Johnson\&Davis 2003, Lee et al 2001, Torget et al 2000]. Some parasitic degradation pathways leading to the formation of noncellulosic polymeric materials were also suggested [Abatzoglou et al 1986, Johnson\&Davis 2003]. However, the detailed mechanisms for these parasitic reactions are not known. For furfural and HMF formation, some researchers [Garrett et al 1969, Parker et al 2000] have proposed degradation pathways that proceed via a series of open-chain intermediates. In contrast, Antal and coworkers [Antal et al 1991] have proposed a mechanism based on a 2,5anhydride intermediate for xylose degradation leading to furfural. Nevertheless, the precise mechanism for the formation of furfural and HMF remains an open question. 


\section{Results and Discussion}

$A b$ initio MD simulation [CPMD3.7] was used to investigate acidic xylose and glucose degradation pathways at $500 \mathrm{~K}$, conditions known to result in severe sugar degradation during prehydrolysis [Torget et al 2000]. The basic idea employed in the simulation is that the first step in sugar degradation under acidic media is the protonation of the $\mathrm{OH}$ groups on the xylose and glucose rings. Since there are four and five $\mathrm{OH}$ groups on the xylose and glucose rings, respectively; it is not known which $\mathrm{OH}$ groups will be most prone to attack by a proton. Thus, simulations were conducted for probable protonation of all of the $\mathrm{OH}$ groups. It is found that only protonation of the $\mathrm{OH}$ group on position $\mathrm{C} 2(\mathrm{C} 2-\mathrm{OH})$ leads to a 2,5-anhydride intermediate, which eventually forms furfural and HMF via further elimination of water molecules shown in Figures 1 and 2 for xylose and glucose, respectively. Protonated glucose and xylose at other $\mathrm{OH}$ positions are either stable or degraded to other by-products.

\section{Protonation of $\mathrm{C} 2-\mathrm{OH}$ in $\beta$-xylose}
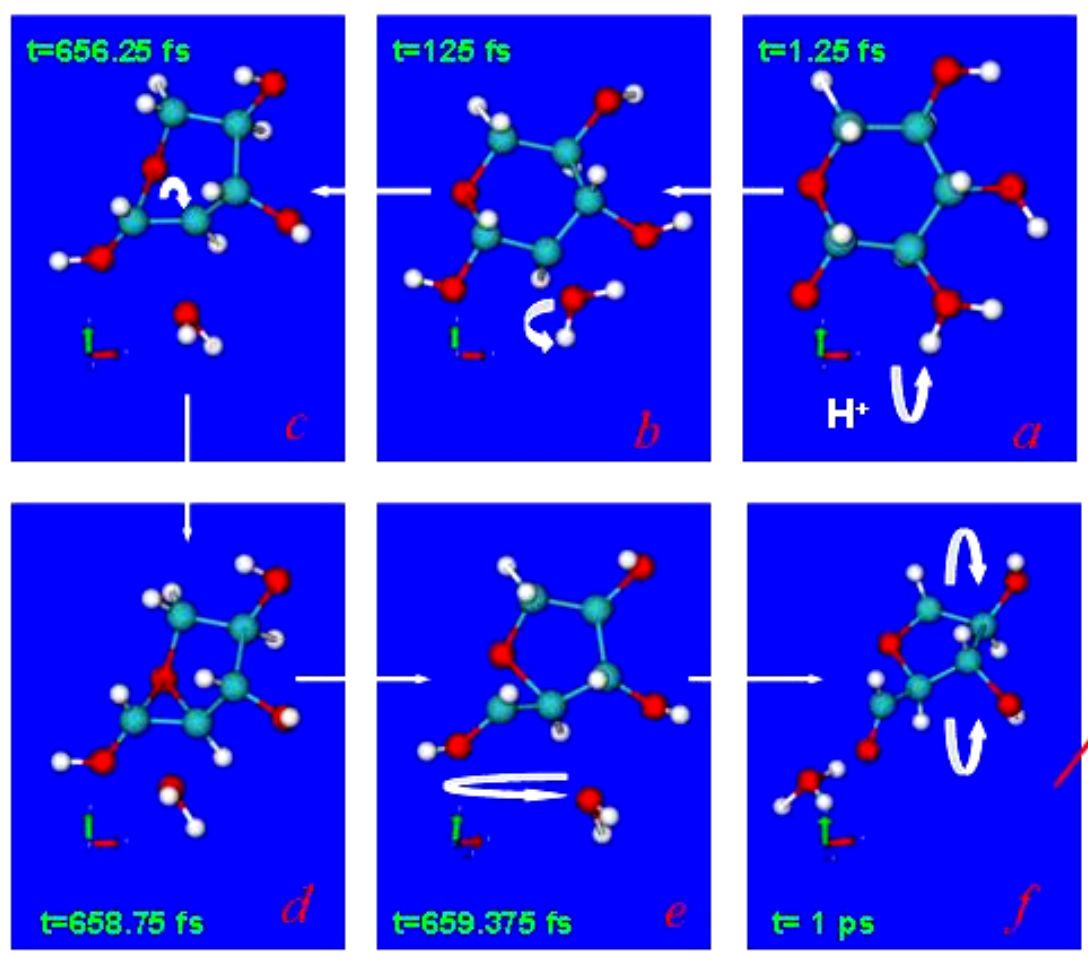

\section{furfural}

Figure 1. Transformation of a protonated $\beta$-xylose $(\mathrm{C} 2-\mathrm{OH})$ into a 2,5-anhydride furfural precursor at $500 \mathrm{~K}$. Each sub-figure $(a-f)$ is a snapshot of the atomic structures at various reaction times shown. a. protonation of $\mathrm{C} 2-\mathrm{OH}$; $b$. water molecule leaves positively charged xylose molecule; $c$. the ring structure deforms due to the presence of positive charge, $\mathrm{C} 2$ and ring $\mathrm{O}$ move closer to each other; $d$. ring $\mathrm{O}$ forms bonds with $\mathrm{C} 1, \mathrm{C} 2$ and $\mathrm{C} 5$ resulting a very short-lived intermediate; $e$. the bond between ring $\mathrm{O}$ and $\mathrm{C} 1$ breaks; $f$. water molecule carries away the excess $\mathrm{H}^{+}$from the $\mathrm{OH}$ at $\mathrm{C} 1$. No open chain form is observed during the reaction. (Symbols: $\mathrm{C}$ (green); $\mathrm{O}$ (red); $\mathrm{H}$ (white)) 
In the case of xylose, this study confirms the mechanism proposed by Antal and coworkers [Antal et al 2000] in that no open chain intermediates to form furfural were present. The oxolane ring in xylose is very stable and does not open up after protonation of the $\mathrm{C} 2-\mathrm{OH}$. The formation of the 2,5-anhydride intermediate (furfural precursor) is very fast and will take less than a picosecond.

\section{Protonation of $\mathrm{C} 2-\mathrm{OH}$ in $\beta$-glucose}
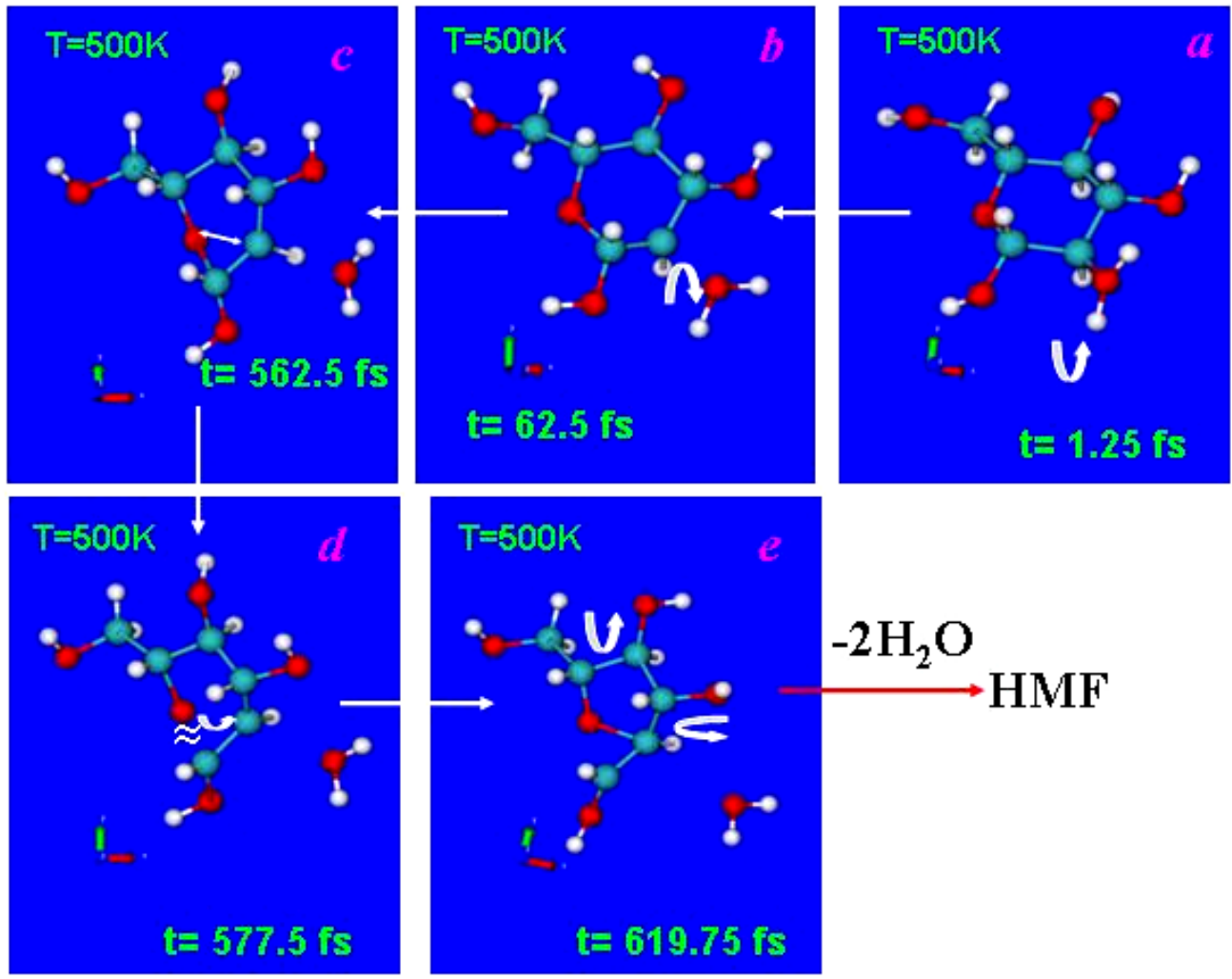

Figure 2. Transformation of a protonated $\beta$-glucose $(\mathrm{C} 2-\mathrm{OH})$ to HMF precursor at $500 \mathrm{~K}$. Each sub-figure $(a-e)$ is a snapshot of the atomic structures at various reaction times shown. a. protonation of $\mathrm{C} 2-\mathrm{OH} ; \quad b$. water molecule leaves positively charged glucose molecule; $c$. the ring structure deforms due to the presence of positive charge, $\mathrm{C} 2$ and ring $\mathrm{O}$ move closer to each other; $d$. ring $\mathrm{O}$ breaks the bond with $\mathrm{C} 1$; $e$. a new bond between ring $\mathrm{O}$ and C2 forms. An open chain form with a very short life-time (<100 fs) $(d)$ is observed during the reaction. (Symbols: C (white); $\mathrm{O}$ (red); $\mathrm{H}$ (white))

In the case of glucose, an open chain form which has a very short life time ( $<100 \mathrm{fs})$ was observed before the formation of 2,5-anhydride intermediate (HMF precursor) as a result of the protonation of the $\mathrm{C} 2-\mathrm{OH}$ (see Figure 2). The differences in reaction pathways between protonated glucose and xylose at $\mathrm{C} 2-\mathrm{OH}$ could perhaps be explained by the stability of their respective positively charged residues. Because glucose has one extra $\mathrm{OH}$ group, this sixmember ring is more positively charged than xylose, considering that oxygen is an electronwithdrawing element compared to carbon. Thus, when the protonated $\mathrm{OH}$ group (i.e. water 
molecule) leaves the ring, the extra positive charge left behind destabilizes the entire ring structure. In the case of glucose, the ring opens up briefly before forming a furan-ring, leaving the extra positive charge to the side methyl-group. In the case of xylose, since the ring is less positively charged compared to glucose, the ring structure is maintained during the formation of furfural precursor.

\section{Acknowledgement}

The authors acknowledge helpful discussions with R. Elander, J. McMillan, R. Torget, and M. Tucker. Funding from the Office of the Biomass Program (OBP) of the United States, Department of Energy (DOE) is gratefully acknowledged. The work was done under subcontract No. ACO-4-33101-01 from the National Renewable Energy Laboratory (NREL).

\section{References}

[Abatzoglou et al 1986] Abatzoglou, N.; Bouchard, J.; Chornet, E.; Overend, R.P. (1986), Can. J. of Chemical Engineering 64, 781-6.

[Antal et al 1990a] Antal, M.J; Mok, W.S.; Richards, G.N. (1990), Carbohydrate Research 199, 91-109;

[Antal et al 1990b] Antal, M.J; Mok, W.S.; Richards, G.N. (1990), Carbohydrate Research 199, 111-115.

[Antal et al 1991] Antal, M.J; Leesomboon,T.; Mok, W.S.; and Richards, G.N. (1991), Carbohydrate Research 217, 71-85.

[Bouchard et al 1992] Bouchard, J.; Overend, R.P.; Chornet, E.; Van Calsteren, M.-R. (1992), J. Wood Chemistry and Technology 12, 335-54.

[CPMD3.7] CPMD3.7, copyrighted jointly by IBM Corp and by Max-Planck Institute, Stuttgart; http://www.cpmd.org.

[Garrett et al 1969] Garrett, E.R and Dvorchik, B.H. (1969), J. Pharmaceutical Sciences, Vol. $58,813-820$.

[Johnson\&Davis 2003] Johnson, D.K.; Davis, M. (2003), Identify Reaction Pathways in Dilute Cellulose Hydrolysis to Improve Mass Balance Closure at High Conversions, NREL Biomass Program P-Milestone Completion Report.

[Lee et al 2001] Lee, Y.Y.; Kim, J.-S.; Xiang, D.Q.; Kim, T-H. (2001), Enhancement of DiluteAcid Total-Hydrolysis Process for High-Yield Saacharification of Cellulosic Biomass, Subcontract Final Report.

[McKibbins et al 1962] McKibbins, S.W.; Harris, J.F.; Saeman, J.F.; and Neill, W.K. (1962), J. Forest Products 19, 17-23.

[Mok et al 1992] Mok, W.S.; Antal Jr., M.J.; Varhegyi, G. (1992), Industrial \& Engineering Chemistry Research 31, 94-1000.

[Parker et al 2000] Parker, S; Calnon, M.; Feinberg, D.; Power, A.; Weiss, C. (2000), The Value of Furfural/Ethanol Coproduction from Acid Hydrolysis Process, SERI/TR-231-2000, Solar Energy Research Institute, Golden, Colorado.

[Torget et al 2000] Torget, R.W.; Kim, J.S.; Lee, Y.Y. (2000), Ind. Eng. Chem. Res. 39, 28172825.

[Van Dam et al 1986] Van Dam, H.E.; Kieboom, A.P.G.; van Bellum, H. (1986), Starch/Stärke 38, 95-101. 